Research Article

Human and Medical Genetics

\title{
Updated birth prevalence and relative frequency of mucopolysaccharidoses across Brazilian regions
}

Juliana Alves Josahkian ${ }^{1,2}$ (D), Franciele Barbosa Trapp ${ }^{3,4,5}$, Maira Graeff Burin ${ }^{3,4,5}$, Kristiane MichelinTirelli ${ }^{3,4,5}$, Ana Paula Pereira Scholz de Magalhães ${ }^{3,4,5}$, Fernanda Medeiros Sebastião ${ }^{3,4,5}$, Fernanda Bender ${ }^{3,4,5}$, Jurema Fátima De Mari ${ }^{3,4}$, Ana Carolina Brusius-Facchin ${ }^{3,4,5}$, Sandra Leistner-Segal ${ }^{3,4,5}$ (D), Diana Rojas Málaga $^{6}$ and Roberto Giugliani ${ }^{2,3,4,5,7,8,9}$ (i)

${ }^{1}$ Hospital Universitário de Santa Maria, Unidade de Clínica Médica, Santa Maria, RS, Brazil.

${ }^{2}$ Universidade Federal do Rio Grande do Sul, Programa de Pós-Graduação em Genética e Biologia

Molecular, Porto Alegre, RS, Brazil.

${ }^{3}$ Rede MPS Brasil, Porto Alegre, RS, Brazil.

${ }^{4}$ Hospital de Clínicas de Porto Alegre, Serviço de Genética Médica, Porto Alegre, RS, Brazil.

${ }^{5}$ Hospital de Clínicas de Porto Alegre, Centro de Pesquisa Experimental, Grupo de Pesquisa

BIODISCOVERY, Porto Alegre, RS, Brazil.

${ }^{6}$ Grupo Fleury, Pesquisa e Desenvolvimento - Biologia Molecular, São Paulo, SP, Brazil.

${ }^{7}$ Universidade Federal do Rio Grande do Sul, Departamento de Genética, Porto Alegre, RS, Brazil.

${ }^{8}$ Instituto Nacional de Genética Médica Populacional (INAGEMP), Porto Alegre, RS, Brazil.

${ }^{9}$ Hospital de Clínicas de Porto Alegre, Centro de Pesquisa Clínica, Grupo de Pesquisa DRBRASIL, Porto

Alegre, RS, Brazil.

\begin{abstract}
The mucopolysaccharidoses (MPS) are a group of lysosomal storage disorders caused by 11 enzyme deficiencies, classified into seven types. Data on the birth prevalence of each MPS type are available for only a few countries, and the totality of cases may be underestimated. To determine the epidemiological profile of MPS in each Brazilian region, we analyzed data collected between 1982 and 2019 by a national reference laboratory and identified 1,652 patients. Using data between 1994 and 2018, the birth prevalence (by 100,000 live births) for MPS was 1.57. MPS II was the most common type of MPS in Brazil, and its birth prevalence was 0.48 (0.94 considering only male births). Regarding the number of cases per region, MPS II was the most frequent in the North and Center-West (followed by MPS VI), and also in the Southeast (followed by MPS I); MPS I and MPS II were the most common types in the South; and MPS VI was the most common in the Northeast (followed by MPS II). The differences observed in the relative frequencies of MPS types across Brazilian regions are likely linked to founder effect, endogamy, and consanguinity, but other factors may be present and need further investigation.
\end{abstract}

Keywords: Lysosomal storage diseases, metabolic diseases, mucopolysaccharidoses, epidemiology, Brazil.

Received: April 30, 2020; Accepted: December 04, 2020.

\section{Introduction}

Mucopolysaccharidoses (MPS) are a group of lysosomal storage disorders caused by the deficiency of enzymes involved in the catabolism of glycosaminoglycans (GAGs). These conditions are multisystemic, progressive, and have variable clinical features (Neufeld and Muenzer, 2014), not only among the different types but also among patients with the same type of MPS. Severe cases are easier to diagnose, but attenuated cases are challenging to recognize and can be confounded with more common pathologies (Suarez-Guerrero et al., 2015).

Studies of the specific enzymes involved in different steps of the GAG degradation pathway and the identification of which genes cause the disease allowed the classification of MPS in seven clinical types, which correspond to 11 enzyme

Send correspondence to Juliana Alves Josahkian. Hospital Universitário de Santa Maria, Departamento de Clínica Médica, Av. Roraima, 1000, prédio 22, Camobi, 97105-900, Santa Maria, RS, Brazil. Email: julianajosahkian@gmail.com. deficiencies, currently recognized as MPS I, II, III (A, B, C, and D subtypes), IV (A and B subtypes), VI, VII, and IX. All MPS are autosomal recessive disorders, except MPS II, which is an X-linked recessive condition (Neufeld and Muenzer, 2014).

Epidemiological data about the MPS types are available for only a few countries and regions, and its birth prevalence may be underestimated as a consequence of the clinical heterogeneity of this group of diseases and the difficulties for its laboratory investigation (Giugliani, 2012). For this reason, a laboratory to provide diagnostic support for MPS was established at the Medical Genetics Service of Hospital de Clínicas de Porto Alegre (MGS/HCPA), Brazil. MGS/HCPA is a well-known reference center in the country, and it has received samples from patients with suspected MPS since 1982 (Giugliani et al., 2017). In 2004, the demand for testing patients suspected of having MPS led to the creation of the MPS Brazil Network, with a specific investigation workflow (Giugliani et al., 2016). In this manner, this study aimed to report the 
birth prevalence and relative frequency of the different MPS types in Brazil to determine the epidemiological profile of this condition per state, per region and in the country as a whole.

\section{Material and Methods}

We analyzed the records from the MGS/HCPA and the MPS Brazil Network of patients diagnosed with MPS between 1982 and 2019. MPS cases were diagnosed biochemically; the investigation frequently starts with a quantitative (colorimetric method with dimethylene blue) and qualitative (electrophoresis) analysis of urinary GAGs, followed by specific enzyme assays according to the first results and/or by identification of pathogenic variants by molecular genetic analysis. In this study, we calculated the relative frequency of each MPS type in Brazil, and also present data by region and state.

In this report we use the term birth prevalence to refer to the number of MPS cases diagnosed by the total number of live births in a specific period expressed as cases per 100,000 live births, as employed previously in the literature (Poupetová et al., 2010; Khan et al., 2017).

Data regarding live births from the Brazilian Health System database were available from 1994 to 2018, allowing us to calculate the birth prevalence in this period. Patients with MPS who were not born during this period were not included in the analyzes. The comparison between our findings and the estimations from other countries is also presented.

\section{Results}

From 1982 to 2019, 1,652 Brazilian patients were diagnosed with MPS at the Medical Genetics Service of Hospital de Clínicas de Porto Alegre. MPS II was the most commonly diagnosed condition (493 cases, 29.84\%), followed by MPS VI (351 cases, 21.25\%), MPS I (315 cases, 19.07\%), MPS III - all subtypes (267 cases, 16.16\%), MPS IV - both subtypes (205 cases, 12.41\%) and MPS VII (21 cases, 1.27\%). We did not observe any patients diagnosed with MPS IX.

Regarding MPS III, we identified the specific subtype (A, B, C, or D) for $95.50 \%$ of the cases. In this subset, the proportion of MPS IIIA was $26.67 \%$; for IIIB, $45.49 \%$; for IIIC, $27.45 \%$; and there was just one case of IIID (0.39\%).

The same approach was employed for MPS IV. In $96.09 \%$ of the cases, we were able to identify each specific subtype (A or B). In this subset, the proportion of MPS IVA was $96.45 \%$, and the percentage of MPS IVB was $3.55 \%$. By extrapolating these data to the total number of MPS III and MPS IV cases, we calculated the ratios presented in Table 1.

When considering the number of cases diagnosed from each Brazilian region, we found that MPS II was the most frequent in the North, Center-West, and Southeast regions; MPS I and MPS II were tied as the most common types in the South region; and MPS VI was the most frequent in the Northeast region. The number of cases diagnosed according to the Brazilian region and state of origin is shown in Table 1, and the distribution of these types of MPS in Brazil is shown in Figure 1.

Based on data provided by the Information System on Live Births (SINASC) of the Brazilian Health System database, between 1994 and 2018, a total of 74,215,086 live births occurred in Brazil - 37,977,308 being male babies
(DATASUS, 2020). We are aware of 1,164 Brazilian patients diagnosed with MPS who were born in Brazil during this period. Among these patients, 217 were MPS I, 358 were MPS II, 199 were MPS III (54 IIIA, 84 IIIB, 50 IIIC, 1 IIID, and 10 were MPS III not specified), 117 were MPS IV (110 MPS IVA, 2 MPS IVB, and five with MPS IV not specified), 257 were MPS VI and 16 were MPS VII. For calculation purposes, the unspecified cases were distributed proportionally according to the frequency of MPS subtype. Thus, the numbers were adjusted to 57 for MPS IIIA, 88 for MPS IIIB, 53 for MPS IIIC, and 115 for MPS IVA.

The calculated incidence for MPS in Brazil, using the 1994 to 2018 data, was $1.57 / 100,000$ live births. Regarding each MPS type, the birth prevalence by 100,000 live births was 0.29 for MPS I, 0.48 for MPS II (or 0.94, considering only male births), 0.08 for MPS IIIA, 0.12 for MPS IIIB, 0.07 for MPS IIIC, 0.001 for MPS IIID, 0.15 for MPS IVA, 0.003 for MPS IVB, 0.35 for MPS VI, 0.02 for MPS VII, and 0 for MPS IX.

The birth prevalence was also calculated for each Brazilian region. For the 358 patients $(30.76 \%)$ without an informed place of birth, the region from where samples were obtained was set as "place of birth." Our results showed that MPS II had the highest score in all Brazilian regions, except in the Northeast, where MPS VI presented the highest birth prevalence rate. The number of cases diagnosed and the birth prevalence for MPS patients born from 1994 to 2018 in Brazil and each region of this country is detailed in Table 2.

This study was approved by the Ethics Committee of Universidade Federal do Rio Grande do Sul, Brazil (CAAE \#82189417.5.0000.5347). This study was conducted in accordance with the ethical standards from the 1964 Declaration of Helsinki and its later amendments. Our manuscript does not contain data from any individual person.

\section{Discussion}

In this study, we explored the epidemiological data of MPS in Brazil. MPS II was the most common type of MPS in Brazil and the second most common lysosomal storage disease diagnosed in our laboratory in previously published studies conducted by our group (Giugliani et al., 2017). Since Brazil has continental dimensions, analysis per region was critical for showing that MPS II is the most common in the North, Southeast, and Center-West. Indeed, MPS I and MPS II were tied as the most common types in the South, and MPS VI was the most frequent in the Northeast.

Birth prevalence rates calculated from 1994 to 2018 indicated that MPS II was the most frequent in all regions except the Northeast, where MPS VI has the highest rate. A founder effect that resulted in a high frequency of p.H178L pathogenic variant in the $A R S B$ gene, responsible for MPS VI, may explain the high number of cases in Brazil's Northeast (Federhen et al., 2020). This region also has areas of geographical isolation, endogamy, and a high number of consanguineous marriages that may lead to increased rates of MPS VI patients (Costa-Motta et al., 2014; Vairo et al., 2015). In addition, the birth prevalence of MPS II in the Northeast was similar to the one observed in other regions of Brazil, which suggests that the higher incidence of MPS VI 
Table 1 - MPS types diagnosed in Brazil per region and by state ${ }^{a}$ from 1982 to 2019.

\begin{tabular}{|c|c|c|c|c|c|c|c|c|c|c|c|c|}
\hline Region/State & All & I & II & IIIA & IIIB & IIIC & IIID & IVA & IVB & VI & VII & IX \\
\hline North & 75 & 13 & 30 & 2 & 4 & 2 & - & 5 & - & 18 & 1 & - \\
\hline Acre & 7 & 2 & 1 & - & 1 & - & - & 2 & - & 1 & - & - \\
\hline Amazonas & 31 & 6 & 10 & 1 & 1 & - & - & 1 & - & 12 & - & - \\
\hline Amapá & - & - & - & - & - & - & - & - & - & - & - & - \\
\hline Pará & 28 & 3 & 13 & 1 & 2 & 2 & - & 1 & - & 5 & 1 & - \\
\hline Rondônia & 7 & 1 & 5 & - & - & - & - & 1 & - & - & - & - \\
\hline Roraima & 1 & - & 1 & - & - & - & - & - & - & - & - & - \\
\hline Tocantins & 1 & 1 & - & - & - & - & - & - & - & - & - & - \\
\hline Center-West & 103 & 20 & 33 & 6 & 8 & 3 & - & 6 & - & 24 & 3 & - \\
\hline Distrito Federal & 49 & 12 & 9 & 4 & 4 & 2 & - & 4 & - & 13 & 1 & - \\
\hline Goiás & 22 & 2 & 11 & 2 & - & - & - & 1 & - & 6 & - & - \\
\hline Mato Grosso & 15 & 5 & 6 & - & 3 & - & - & 1 & - & - & - & - \\
\hline Mato Grosso do Sul & 17 & 1 & 7 & - & 1 & 1 & - & - & - & 5 & 2 & - \\
\hline Southeast & 679 & 140 & 207 & 33 & 56 & 37 & - & 69 & 6 & 124 & 7 & - \\
\hline Espírito Santo & 22 & - & 11 & 1 & 4 & 2 & - & - & - & 3 & 1 & - \\
\hline Minas Gerais & 135 & 33 & 22 & 7 & 15 & 5 & - & 15 & - & 36 & 2 & - \\
\hline São Paulo & 388 & 86 & 126 & 21 & 23 & 24 & - & 36 & 6 & 62 & 4 & - \\
\hline Rio de Janeiro & 134 & 21 & 48 & 4 & 14 & 6 & - & 18 & - & 23 & - & - \\
\hline Northeast & 510 & 66 & 147 & 22 & 14 & 19 & 1 & 68 & 1 & 162 & 10 & - \\
\hline Alagoas & 34 & 4 & 23 & 1 & - & 1 & - & - & - & 5 & - & - \\
\hline Bahia & 111 & 15 & 34 & 6 & 7 & 1 & 1 & 9 & 1 & 31 & 6 & - \\
\hline Ceará & 88 & 11 & 35 & 5 & 6 & 3 & - & 7 & - & 21 & - & - \\
\hline Maranhão & 23 & 2 & 11 & 2 & 1 & - & - & 3 & - & 4 & - & - \\
\hline Paraíba & 71 & 8 & 6 & 1 & - & 9 & - & 26 & - & 20 & 1 & - \\
\hline Pernambuco & 118 & 15 & 20 & 2 & - & 5 & - & 17 & - & 58 & 1 & - \\
\hline Piauí & 19 & 2 & 7 & 1 & - & - & - & 2 & - & 5 & 2 & - \\
\hline Rio Grande do Norte & 31 & 6 & 4 & 2 & - & - & - & 4 & - & 15 & - & - \\
\hline Sergipe & 15 & 3 & 7 & 2 & - & - & - & - & - & 3 & - & - \\
\hline South & 285 & 76 & 76 & 8 & 40 & 12 & - & 50 & - & 23 & - & - \\
\hline Paraná & 102 & 20 & 39 & 3 & 12 & 3 & - & 13 & - & 12 & - & - \\
\hline Rio Grande do Sul & 142 & 42 & 32 & 3 & 21 & 6 & - & 28 & - & 10 & - & - \\
\hline Santa Catarina & 41 & 14 & 5 & 2 & 7 & 3 & - & 9 & - & 1 & - & - \\
\hline Brazil, total & 1652 & 315 & 493 & 71 & 122 & 73 & 1 & 198 & 7 & 351 & 21 & - \\
\hline
\end{tabular}

a For MPS IIIA, IIIB, IIIC, and IIID, and for MPS IVA and IVB, the numbers represent an extrapolation.

is related to these factors, and not to a lower absolute number of births with MPS II. Similarly, as in Brazil, MPS II is the most common type found in Estonia, Taiwan, Japan, South Korea, China, and Switzerland (Krabbi et al., 2012; Cho et al., 2014; Chen et al., 2016; Khan et al., 2017). The higher birth prevalence of MPS II in East Asia was suggested to be a consequence of the p.R468 pathogenic variants in the IDS gene (Khan et al., 2017). In South Korea, IDS-IDS2 recombination mutations were the most frequently (Cho et al., 2014). Molecular analysis of 103 unrelated South-Americans (including 91 Brazilian individuals) MPS II patients showed that small insertions, deletions, indels, and point mutations in the IDS gene were responsible for the disease in $81 \%$ of cases. Inversion/disruption or partial/total deletions of the IDS gene were found in $19 \%$ of the patients, and only eight pathogenic variants were found in more than one unrelated patient (Brusius-Facchin et al., 2014). We do not have information about the rate of "de novo" mutation in the IDS gene in Brazil, but data from Latin America the literature estimate it as 10\% (Amartino et al., 2014).

A limitation of our study is that, although responsible for the vast majority of MPS diagnosis in Brazil, our laboratory is not the only to perform such tests, and some Brazilian cases may have been not included. Also, milder cases that are challenging to diagnose may be overlooked. Another estimate of the birth prevalence of MPS in Brazil, based on the frequency of heterozygotes for the most common pathogenic variant of the IDUA gene (p.Trp402Ter) in healthy blood donors and on the relative frequency of homozygosity for such variant in MPS I patients (Federhen et al., 2020) was reported as 


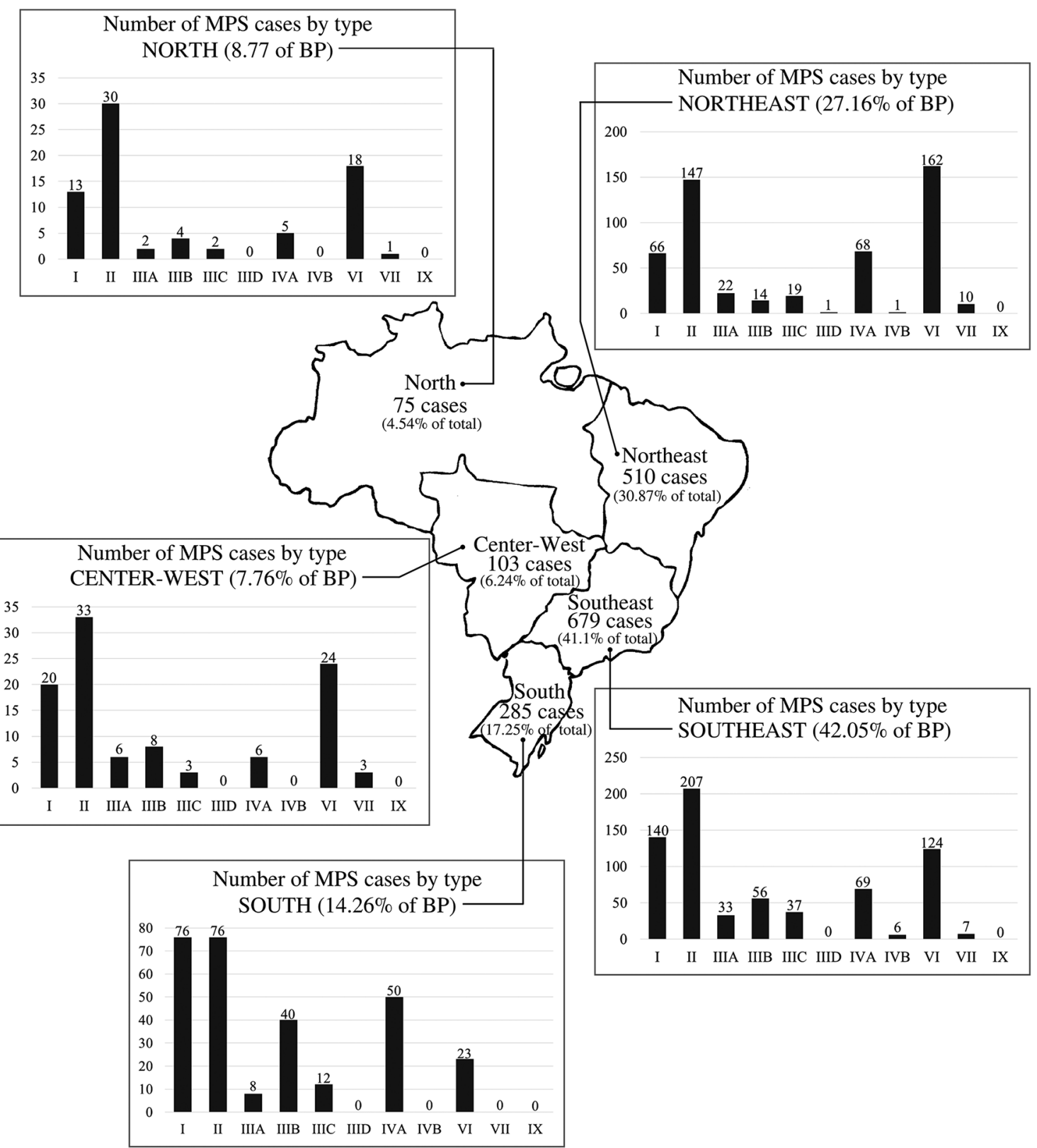

Figure 1 - Distribution according to Brazilian region of the Brazilian MPS cases diagnosed at the Medical Genetics Service of Hospital de Clínicas de Porto Alegre from 1982 to 2019 (BP: Brazilian population as estimated in 2019) (IBGE, 2020).

4.62/100,000 live births, nearly three times higher than the one found in this study (1.57). In this manner, although providing a comprehensive picture of the epidemiological profile of MPS in Brazil, the absolute numbers found in this study are possibly underestimated. A newborn screening (NBS) program would be more accurate to estimate the incidence of MPS. Although MPS testing is not included in the public NBS program in Brazil, pilot studies are being carried out in order to evaluate its feasibility for future incorporation (Camargo Neto et al., 2018).

A previous estimation of the birth prevalence of MPS in Brazil was published with data from 1994 to 2015 (Federhen et al., 2020). We have updated the birth prevalence across Brazilian regions up to 2018 and also demonstrated the distribution of MPS across each Brazilian State. We think this revision is important since the inclusion of only three years already demonstrated a change in the estimated birth prevalence of MPS by type in the South Region, where MPS I was previously the most common (Federhen et al., 2020). Moreover, the knowledge of the distribution by state, which does not necessarily reflects the distribution by region, can help the design of targeted public policies. This report provides a comprehensive characterization of the epidemiological profile of the different MPS subtypes in Brazil and its variations across states and regions. The birth prevalence of MPS is variable across countries and regions and is likely linked to founder effect, endogamy, and consanguinity, but other factors that are still unclear may be present and may need further investigation. Our findings may help the assess of health needs in distinct populations and the delivery of medical care for these rare diseases. 
Table 2 - Number of cases diagnosed and incidence (by 100,000 live births) ${ }^{\mathrm{a}}$ calculated for MPS patients born from 1994 to 2018 in Brazil and by region.

\begin{tabular}{|c|c|c|c|c|c|c|c|c|c|c|c|c|}
\hline Region $M P S$ & All & I & II & IIIA & IIIB & IIIC & IIID & IVA & IVB & VI & VII & IX \\
\hline North & $\begin{array}{c}65 \\
(0.88)\end{array}$ & $\begin{array}{c}13 \\
(0.18)\end{array}$ & $\begin{array}{c}28 \\
(0.38) \\
(0.74)^{\mathrm{b}}\end{array}$ & $\begin{array}{c}2 \\
(0.03)\end{array}$ & $\begin{array}{c}4 \\
(0.05)\end{array}$ & $\begin{array}{c}2 \\
(0.03)\end{array}$ & - & $\begin{array}{c}4 \\
(0.05)\end{array}$ & - & $\begin{array}{c}11 \\
(0.15)\end{array}$ & $\begin{array}{c}1 \\
(0.01)\end{array}$ & - \\
\hline Northeast & $\begin{array}{c}379 \\
(1.78)\end{array}$ & $\begin{array}{c}52 \\
(0.25)\end{array}$ & $\begin{array}{c}109 \\
(0.51) \\
(1.00)^{b}\end{array}$ & $\begin{array}{c}18 \\
(0.08)\end{array}$ & $\begin{array}{c}13 \\
(0.06)\end{array}$ & $\begin{array}{c}14 \\
(0.07)\end{array}$ & $\begin{array}{c}1 \\
(0.005)\end{array}$ & $\begin{array}{c}40 \\
(0.19)\end{array}$ & - & $\begin{array}{c}123 \\
(0.58)\end{array}$ & $\begin{array}{c}9 \\
(0.04)\end{array}$ & - \\
\hline Center-West & $\begin{array}{c}73 \\
(1.26)\end{array}$ & $\begin{array}{c}14 \\
(0.24)\end{array}$ & $\begin{array}{c}27 \\
(0.47) \\
(0.91)^{\mathrm{b}}\end{array}$ & $\begin{array}{c}2 \\
(0.03)\end{array}$ & $\begin{array}{c}8 \\
(0.14)\end{array}$ & $\begin{array}{c}1 \\
(0.02)\end{array}$ & - & $\begin{array}{c}2 \\
(0.03)\end{array}$ & - & $\begin{array}{c}17 \\
(0.29)\end{array}$ & $\begin{array}{c}2 \\
(0.03)\end{array}$ & - \\
\hline Southeast & $\begin{array}{c}476 \\
(1.62)\end{array}$ & $\begin{array}{c}98 \\
(0.33)\end{array}$ & $\begin{array}{c}143 \\
(0.49) \\
(0.95)^{\mathrm{b}}\end{array}$ & $\begin{array}{c}27 \\
(0.09)\end{array}$ & $\begin{array}{c}41 \\
(0.14)\end{array}$ & $\begin{array}{c}27 \\
(0.09)\end{array}$ & - & $\begin{array}{c}43 \\
(0.15)\end{array}$ & $\begin{array}{c}2 \\
(0.007)\end{array}$ & $\begin{array}{c}91 \\
(0.31)\end{array}$ & $\begin{array}{c}4 \\
(0.01)\end{array}$ & - \\
\hline South & $\begin{array}{c}171 \\
(1.66)\end{array}$ & $\begin{array}{c}40 \\
(0.39)\end{array}$ & $\begin{array}{c}51 \\
(0.49) \\
(0.97)^{b}\end{array}$ & $\begin{array}{c}8 \\
(0.08)\end{array}$ & $\begin{array}{c}22 \\
(0.21)\end{array}$ & $\begin{array}{c}9 \\
(0.09)\end{array}$ & - & $\begin{array}{c}26 \\
(0.25)\end{array}$ & - & $\begin{array}{c}15 \\
(0.15)\end{array}$ & - & - \\
\hline Brazil, total & $\begin{array}{c}1164 \\
(1.57)\end{array}$ & $\begin{array}{c}217 \\
(0.29)\end{array}$ & $\begin{array}{c}358 \\
(0.48) \\
(0.94)^{\mathrm{b}}\end{array}$ & $\begin{array}{c}57 \\
(0.08)\end{array}$ & $\begin{array}{c}88 \\
(0.12)\end{array}$ & $\begin{array}{c}53 \\
(0.07)\end{array}$ & $\begin{array}{c}1 \\
(0.001)\end{array}$ & $\begin{array}{c}115 \\
(0.15)\end{array}$ & $\begin{array}{c}2 \\
(0.003)\end{array}$ & $\begin{array}{c}257 \\
(0.35)\end{array}$ & $\begin{array}{c}16 \\
(0.02)\end{array}$ & - \\
\hline
\end{tabular}

${ }^{\mathrm{a}}$ The incidence rate (shown inside parenthesis) was calculated using our data and the number of live births obtained from SINASC; ${ }^{\mathrm{b}}$ Considering only male live births.

\section{Acknowledgments}

The authors would like to thank the biologists, biochemists, biomedical, undergraduate, and graduate students who contributed to the work developed by the MPS BRASIL NETWORK. We would also acknowledge the health professionals who are members of this network and provided samples from suspected MPS patients. The authors acknowledge the support received from INAGEMP (CNPQ 465549/2014, CAPES 88887.136366/2017-00, FAPERGS 17/2551.0000521-0), from FIPE/HCPA (projects GPPG 20030066 and 2017-0664), and from Fundação Médica do Rio Grande do Sul. This work was performed in collaboration with the BIODISCOVERY (Experimental Research Centre, HCPA, Porto Alegre, Brazil) and DRBRASIL (Clinical Research Centre, HCPA, Porto Alegre Brazil) research groups.

\section{Conflict of Interest}

The authors declare that they have no conflict of interest.

\section{Author Contributions}

JAJ and RG conceived this study; JAJ performed formal analysis and wrote the manuscript; RG supervised the study and fully revised the document; RG, FBT, MGB, KMT, APPSM, FMS, FB, JFDM, ACBF, SLS and DRM contributed to the investigation, data collection, and creation of MPS BRAZIL NETWORK online platform. All authors read and approved the final version.

\section{References}

Amartino H, Ceci R, Masllorens F, Gal A, Arberas C, Bay L, Ilari R, Dipierri J, Specola N, Cabrera A, et al. (2014). Identification of 17 novel mutations in 40 Argentinian unrelated families with mucopolysaccharidosis type II (Hunter syndrome). Mol Genet Metab Rep 1:401-406.
Brusius-Facchin AC, Schwartz IV, Zimmer C, Ribeiro MG, Acosta AX, Horovitz D, Monlleó IL, Fontes MIB, Fett-Conte A, Oliveira Sobrinho RP, et al. (2014) Mucopolysaccharidosis type II: Identification of 30 novel mutations among Latin American patients. Mol Genet Metab 111:133-138.

Camargo Neto E, Schulte J, Pereira J, Bravo H, Sampaio-Filho C and Giugliani R (2018). Neonatal screening for four lysosomal storage diseases with a digital microfluidics platform: Initial results in Brazil. Genet Mol Biol 41:414-416.

Chen X, Qiu W, Ye J, Han L, Gu X and Zhang H (2016) Demographic characteristics and distribution of lysosomal storage disorder subtypes in Eastern China. J Hum Genet 61:345-349.

Cho SY, Sohn YB and Jin DK (2014) An overview of Korean patients with mucopolysaccharidosis and collaboration through the Asia Pacific MPS Network. Intractable Rare Dis Res 3:79-86.

Costa-Motta FM, Bender F, Acosta A, Abé-Sandes K, Machado T, Bomfim T, Boa Sorte T, Silva D, Bittles A, Giugliani R, et al. (2014) A Community-based study of Mucopolysaccharidosis Type VI in Brazil: The influence of founder effect, endogamy and consanguinity. Hum Hered 77:189-196.

Federhen A, Pasqualim G, de Freitas TF, Gonzalez EA, Trapp F, Matte U and Giugliani R (2020) Estimated birth prevalence of mucopolysaccharidosis in Brazil. Am J Med Genet A 182:469-483.

Giugliani R (2012) Mucopolysacccharidoses: from understanding to treatment, a century of discoveries. Genet Mol Biol 35 Suppl 4:924-931.

Giugliani R, Vairo FP, Riegel M, de Souza CF, Schwartz IV and Pena SD (2016) Rare disease landscape in Brazil: report of a successful experience in inborn errors of metabolism. Orphanet J Rare Dis 11:76.

Giugliani R, Federhen A, Michelin-Tirelli K, Riegel M and Burin M (2017) Relative frequency and estimated minimal frequency of lysosomal storage diseases in Brazil: Report from a reference laboratory. Genet Mol Biol 40:31-39.

Khan SA, Peracha H, Ballhausen D, Wiesbauer A, Rohrbach M, Gautschi M, Manson RW, Giugliani R, Suzuki Y, Orii KE, et al. (2017) Epidemiology of mucopolysaccharidoses. Mol Genet Metab 121:227-240. 
Krabbi K, Joost K, Zordania R, Talvik I, Rein R, Huijmans JG, Verheijen FV and Ounap K (2012) The live-birth prevalence of mucopolysaccharidoses in Estonia. Genetic testing and molecular biomarkers 16:846-849.

Neufeld EF and Muenzer J. The Mucopolysaccharidoses (2014) In: Valle D, Beaudet al., Vogelstein B, Kinzler KW, Antonarakis SE, Ballabio A, Gibson K and Mitchell G. (eds). The Online Metabolic and Molecular Bases of Inherited Disease. McGrawHill, New York, pp. 3421-3452.

Poupetová H, Ledvinová J, Berná L, Dvoráková L, Kozich V and Elleder M (2010) The birth prevalence of lysosomal storage disorders in the Czech Republic: comparison with data in different populations. J Inherit Metab Dis 33:387-396.

Suarez-Guerrero JL, Higuera PJIG, Flórez JSA and Contreras-Garcia GA (2015) Mucopolisacaridosis: características clínicas, diagnóstico y manejo. Rev Chil Pediatr 87:295-304.

Vairo F, Federhen A, Baldo G, Riegel M, Burin M, Leistner-Segal S and Giugliani R (2015) Diagnostic and treatment strategies in mucopolysaccharidosis VI. Appl Clin Genet 8:245-255.

\section{Internet Resources}

DATASUS. Tecnologia da informação a serviço do SUS, http:// tabnet.datasus.gov.br/cgi/deftohtm.exe?sinasc/cnv/nvuf.def (April 25, 2020)

IBGE. Instituto Brasileiro de Geografia e Estatística. Estimativas da população residente no brasil e unidades da federação com data de referência em $1^{\circ}$ de julho de 2019, https://ftp. ibge.gov.br/Estimativas_de_Populacao/Estimativas_2019/ POP2019_20201006.pdf (October 18, 2020)

Associate Editor: Angela Vianna-Morgante

License information: This is an open-access article distributed under the terms of the Creative Commons Attribution License (type CC-BY), which permits unrestricted use, distribution and reproduction in any medium, provided the original article is properly cited. 